Original Article

\title{
Retrospective Study of Surgical Repair of Gunshot Injuries of Peripheral Nerves.
}

\author{
Ridvan Alimehmeti', Gramoz Brace ${ }^{1}$, Ermira Pajaj', Arba Cecia², Thoma \\ Kalefi ${ }^{1}$, Jetmira Kerxhalliu ${ }^{1}$, Arben Rroji ${ }^{1}$, Norik Bardhi ${ }^{1}$, Arsen Seferi ${ }^{1}$
}

https://doi.org/10.32391/ajtes.v3i2.48

\begin{abstract}
Background: Shotgun injuries of the peripheral nerves are presented frequently during the last decades at the Service of Neurosurgery of UHC "Mother Theresa" in Tirana. In such cases the surgical repair of brachial plexus and peripheral nerves constitutes a challenge with relation to difficulties related with mechanism of injury, coexistence of other vascular damage, bone, soft tissue and visceral lesions.

Materials and methods: A retrospective study of operated cases with shotgun injuries treated in our Department from 1997 to 2012 was conducted getting information from clinical charts, surgical registries, intraoperative photos and videos of the surgical repair of peripheral nerves. We performed a thorough analysis of the most influencing factors of surgical outcome such as: age, severity of injury, site of injury with relation to the innervated muscles, type of necessary nerve repair, presence of causalgia before operation, concomitant compromise of vascularization and/or locomotor apparatus. Follow-up of the patient was conducted through out-patient visits and phone interviews going back 10 years from surgical repair.

Results: 68 cases operated for shotgun injury of brachial plexus or peripheral nerves were revised. There were different ages and both sexes involved. The type of nerve repair went from interfascicular neurolysis to direct end-to-end microsuture and nerve grafting. Timely repair of the nerve injury proved to be yielding better result than late repair in terms of pain relief and sensory motor improvement of the preoperative neurological deficit. The degree and the quality of improvement after surgery is related to the type of repair (neurolysis improves better and faster than grafting), the distance from site of injury to the effector muscle (the longer the distance more time it takes for the function to recover). The recovery of the brachial plexus was followed up for many years and further surgery proved to be necessary and of further improvement.

Conclusions: From our long term experience dealing with surgical repair of shotgun injury of peripheral nerves we have learnt that early surgical repair is more efficacious in treating pain and gives better results in terms of motor and sensitive recovery than six months after injury as it was usually done. Long term follow-up is necessary to help with further surgery in case of distal decompressive surgery in anatomical tunnels.
\end{abstract}

Keywords: gunshot injury, peripheral nerve, surgery

*Corresponding Author: Ridvan Alimehmeti

$=凶$ E-mail: ridvanalimehmeti@hotmail.com

${ }^{1}$ Department of Neurosciences, University of Medicine, Service of Neurosurgery, Tirana.

${ }^{2}$ George Mason University, Fairfax Virginia, USA. 


\section{Full Text}

\section{Introduction}

Shotgun injuries may be devastating to neurovascular bundles in proximal and distal sites of the limbs. Whenever the bullet hit the bone there are usually many fragments after the blast which act like cutting objects for the neurovascular bundle.

Whenever a surgical operation is indicated for vascular or bone repair, the nerve should be explored and repaired as well at the same session.

Neuropathic pain is very often observed in shotgun nerve injuries. The timing of surgery seems to influence the effect on pain relief in our series.

\section{Material and Methods}

We have retrospectively recollected operated cases at Service of Neurosurgery, Department of Neurosciences at University Hospital Center "Mother Theresa" in Tirana, for gunshot injuries during the period 1997 2012. The clinical files, intraoperative photos and out-patient archive have been revised and all the patients included in the study have been followed up in out-patient clinic or contacted by phone.

68 patients harboring nerve injuries because of shotgun injury were included in this study. 63 male and 3 female, from 7 to 64 years of age with a median of 27 years old. 17 cases were operated for brachial plexus injury, 32 upper extremities and 24 lower extremities. In 3 cases there were pseudo-aneurysms of the artery at the site of injury which was repaired at the same session. 12 cases were operated previously for internal synthesis of bone fracture, before the patient was send to our attention for nerve repair.

The description of the surgical procedure with the details of the type of nerve repair was revised carefully from the clinical charts and intraoperative photos were retrospectively revised to judge the extent of internal neurolysis or length and number of grafts applied.

At the out-patient clinics all 68 patients were filed and the records on neurological recovery were revised for this retrospective study.

The longest follow-up resulted to be 9,5 years from first nerve surgical repair.

\section{Results}

17 cases with brachial plexus injuries were explored supraclavicular or infraclavicular and in only one case a combined approach was deemed necessary.

In two cases with axillary lump there were an arterial pseudo aneurysm with thrombus which was primary explored with Doppler ultrasound and consecutively wit DSA (digitally subtracted angiography).

Both cases were operated by a combine staff of vascular and neurosurgeon at the same session. Vein graft in one case and artificial prosthesis in the other were done for the axillary artery, before the nerves were repaired.

In 12 cases that were first operated for bone fracture at the site of shotgun injury the nerves were found in an extensive fibrosis which made the dissection of the nerves difficult. In this cases the nerve 
injury was more extensive than those cases which were not associated with bone injury.

In two cases with forearm injury, one of whom 7 years old, there was retraction of the flexor tendons with long-term consequences of growth of the affected limb, which needed further repeated orthopedic operation of tendon transfer. There were 118 nerve elements that were recorded to have been repaired in 68 operated cases. Only 18 needed a sural graft. The rest of the nerve elements were microsurgically repaired through adherentiolysis, longitudinal epineurotomy, interfascicular neurolysis.

All 17 cases of brachial plexus injuries were on severe pain before surgery which improved gradually. In all operated cases none was referring any pain over 3/10 of VAS (visual analogical scale).

In three cases who were followed in outpatient clinics, there were a gradual Tinel sign accompanying nerve regeneration which stopped at the site of distal tunnels, namely cubital and carpal tunnels. Decompression at these sites under local anesthesia proved to be beneficial to sensitive improvement and some motor benefit.

In 32 operated cases for upper extremities injury there were two elements injured in 24 of them and three nerve elements in 8 . All of the cases were studied with Doppler before surgery and ENMG was performed in all cases to confirm the severity of functional compromise of the injured nerves before surgery.

In cases of nerve injuries of lower extremities tibial nerve was interested in
16, peroneal nerve in 18 , sciatic nerve in 7 , femoral nerve in 3 and saphenous nerve in 2 cases. These records report more than the general number of cases (24 cases with lower extremities injury), reflecting multiple nerve injury in most of the cases, in few of them in more than one site due to multiple bullets. All the nerve elements were operated in the same surgical session.

Peroneal nerve did worse recovery than the tibial nerve. Nerve grafts longer than $6 \mathrm{~cm}$ on peroneal nerve did not yield any motor recovery in our operated cases.

All of the patients improved their sole of foot sensation which permitted recovery of infected skin wounds in 7 cases, even years after nerve injury.

Tarsal tunnel distally and proximal tibial and common peroneal nerve at fibular head were opened in cases with clear clinical signs of arrested regeneration after a more proximal nerve injury, which was repaired surgically or not.

60 over 68 operated cases reported pain from 4 to 10 out of 10 in VAS before surgery. The rate of improvement seems to be related to time relapse before surgery and severity of nerve injury and possible surgical repair. The cases operated closely to the time of injury did better recovery from pain then those with chronic neuropathic pain. Patients with more extensive injury of the nerve elements had longer time of recovery from neuropathic pain after surgical repair.

\section{Discussion and conclusion}

To our experience with surgical repair of shotgun nerve injury nerve injuries need to be surgically treated whenever there is clinical neurological deficit of the nerves 
at the trajectory of the bullet. If there is neuropathic pain the timing for surgery should not be prolonged in order to have better result on pain relief. All cases should be closely followed for their clinical neurological recovery which may be arrested in distal anatomical tunnels for the nerves which result to be modified from the changes in terms of gliding tissue and vegetative changes following nerve injuries (more so with shotgun injuries). We like to call it arrested regeneration since the regeneration seems to stop at these sites, which corresponds to permanent Tinel sign in repeated clinical evaluation. In these cases, decompression surgery has proven to be very beneficial in promoting the regeneration of the affected nerves to continue beyond these anatomical tunnels yielding relief of paresthesia and pain, as well as sensitive recovery in the territory of the affected nerve(s).

\section{Case illustration}

21 y.o male sustained gun injury from a near distance at the lower right brachial plexus (figure 1). Palsy of all the brachial plexus elements followed (figure 2). The patient came to our attention 5 weeks from injury with severe pain distal to the right elbow (8/10 of VAS) Tinel sign at axillary neuro-vascular bundle. No arterial injury was detected at Doppler ultrasound. Surgical exploration at the upper part of brachial and axillary area revealed injury of the median ulnar radial and musculocutaneus nerves. All of them were released from adherences and neurolysis was performed under surgical microscope to the extent that no increased consistency of the fascicles was perceived (figure 3). At that time intraoperative nerve action potential was not feasible at our OR, as it is nowadays, so we had to rely of surgeon's experience to decide on type of nerve repair and extend of neurolysis.

The patient did a gradual recovery of the function (figure 4) and in two years he had fully recovered his motor and sensitive function of the upper extremity (figure 5). 


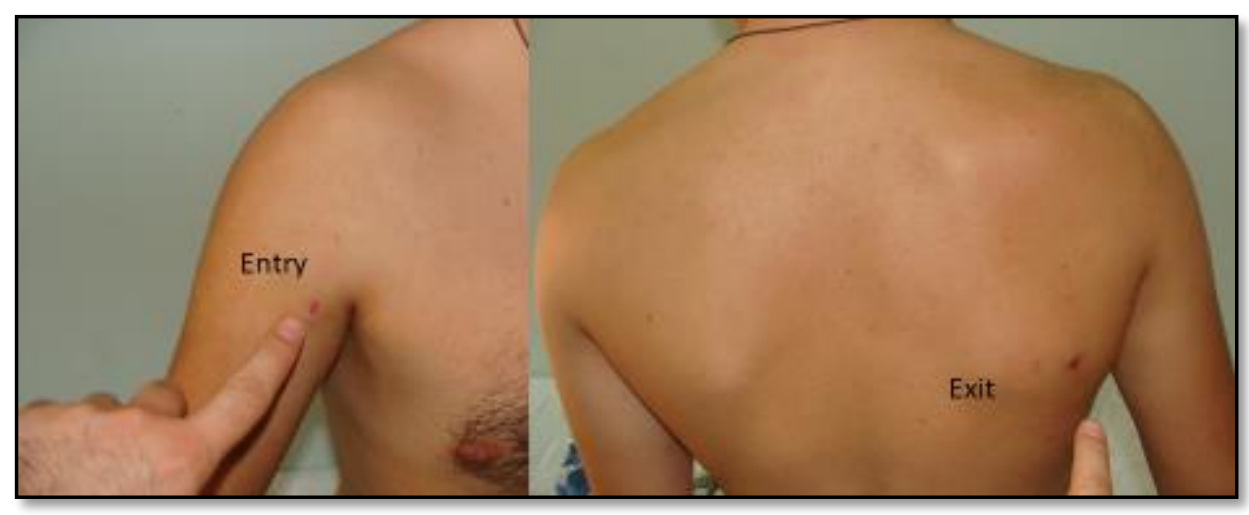

Figure 1: Shows entry and exit points of the bullet.

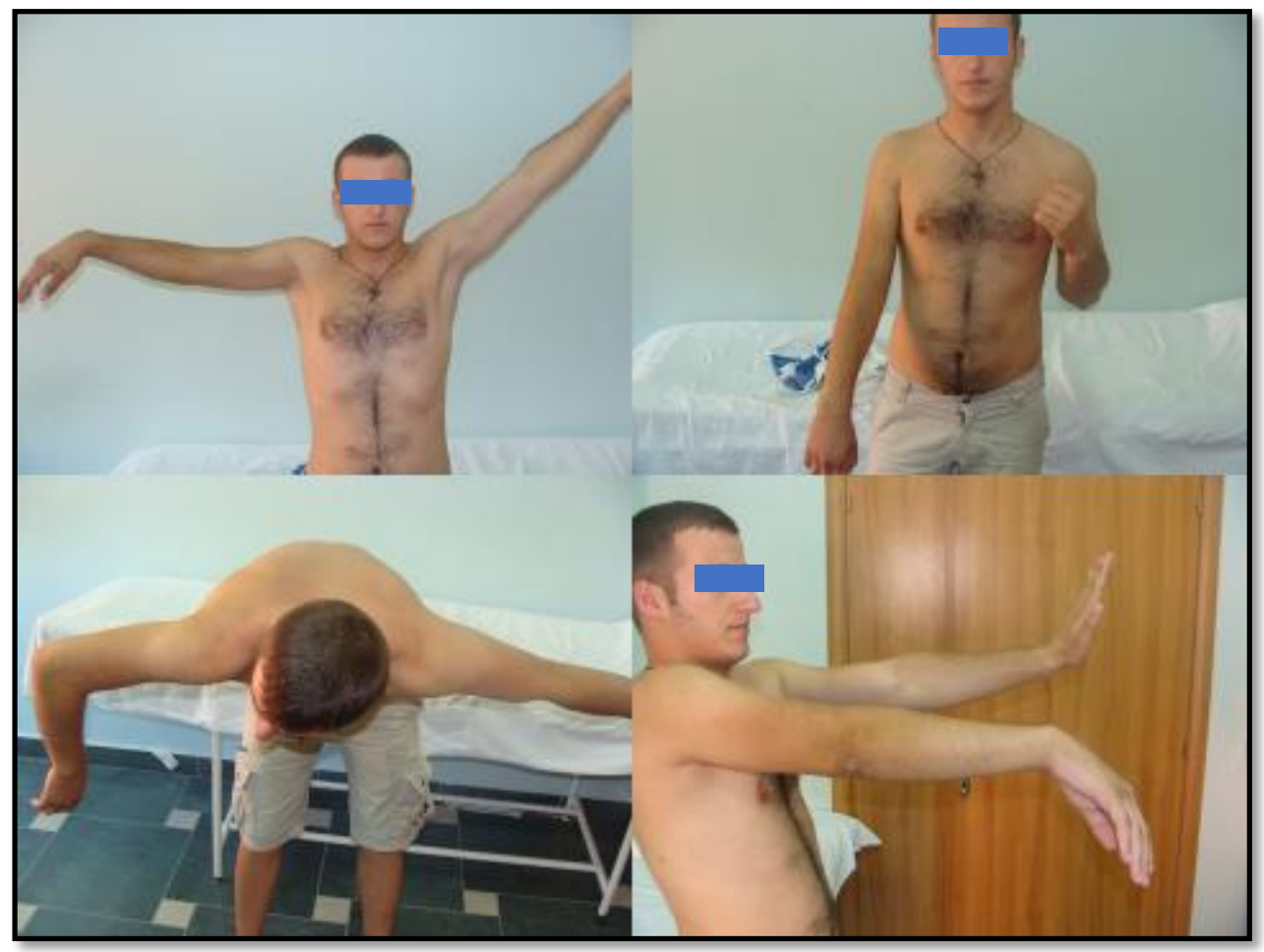

Figure 2: Complete palsy of the radial, median ulnar and musculocutanues nerves. 


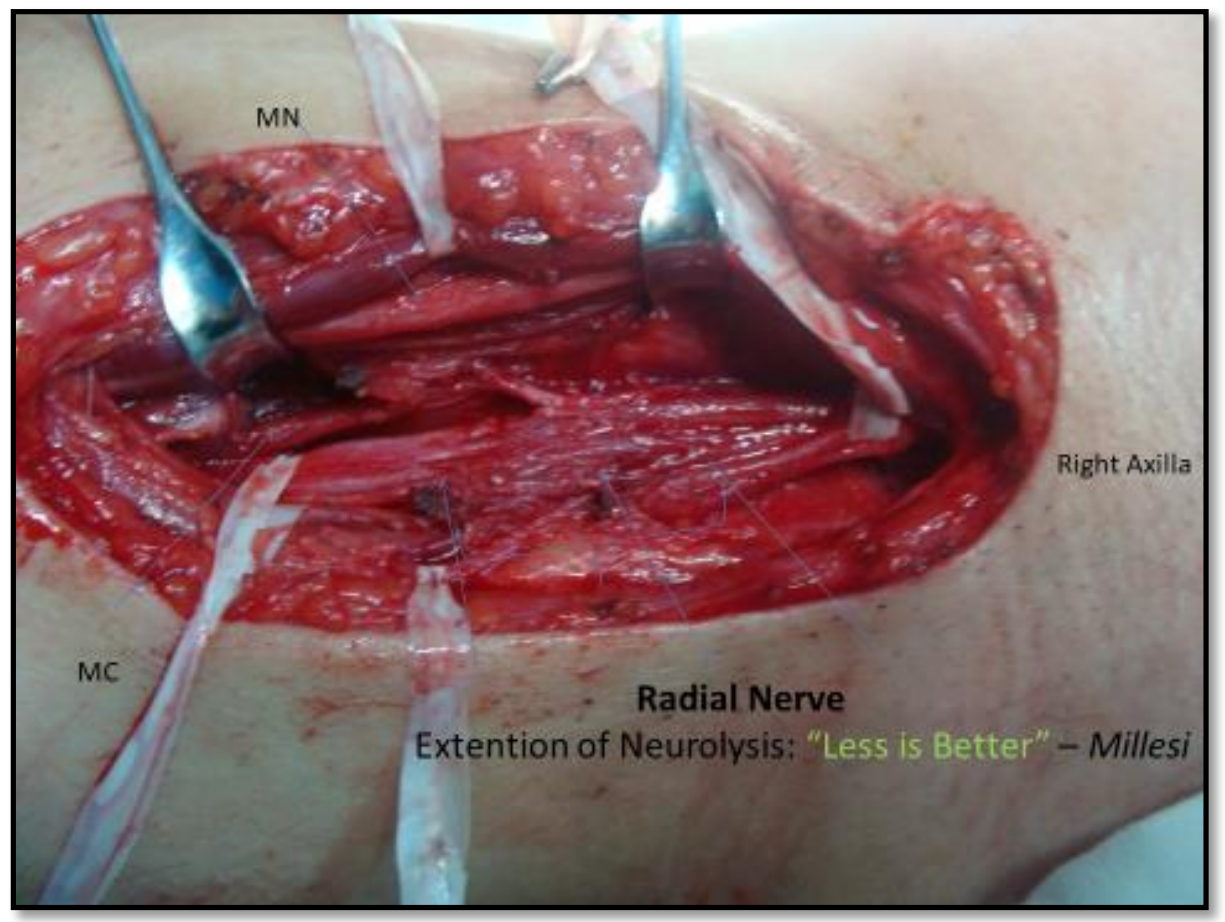

Figure 3: Intraoperative exploration and dissection of the neurovascular structures with neurolysis of the affected nerves.

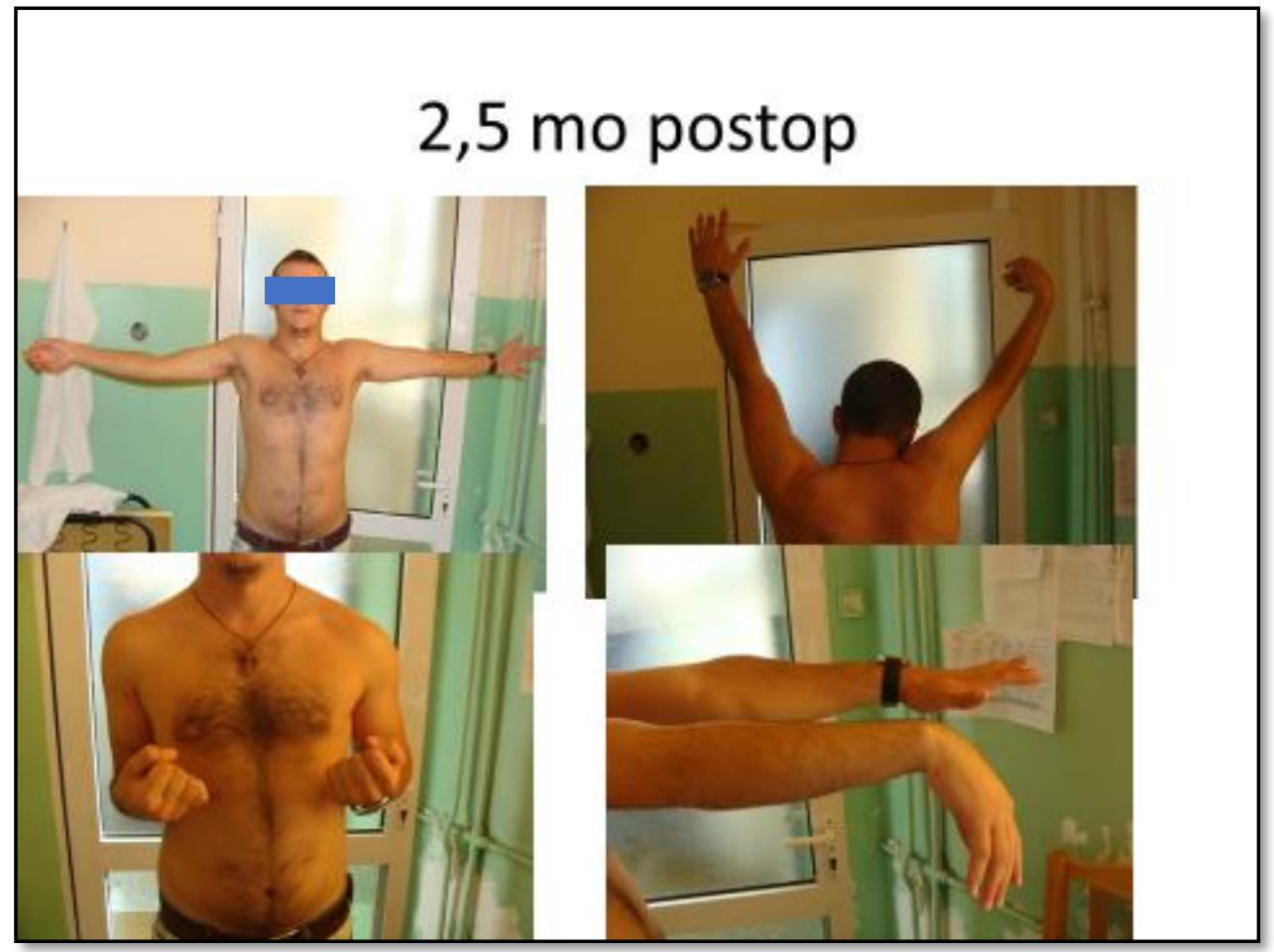

Figure 4: Two and half months from surgery. 


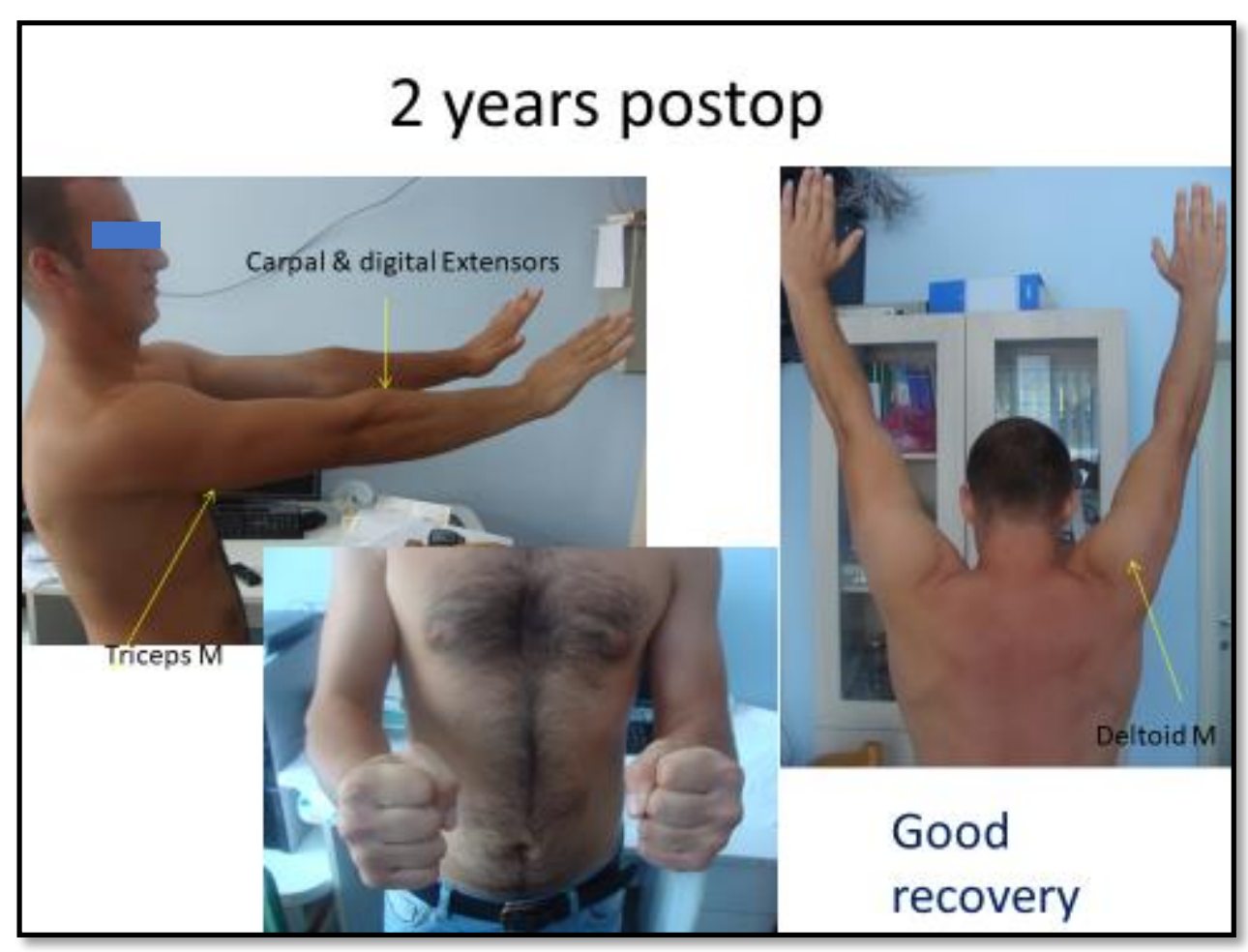

Figure 5: Two years after surgery full neurological recovery.

\section{References}

1. Birch $R$, Misra $P$, Stewart MP, Eardley WG, Ramasamy A, Brown K, Shenoy R, Anand P, Clasper J, Dunn R, Etherington J. Nerve injuries sustained during warfare: part II: Outcomes.

2. J Bone Joint Surg Br. 2012 Apr;94(4):529-35. doi: 10.1302/0301-620X.94B4.28488. PMID: 22434471

3. Bhandari PS, Deb P. Management of Isolated Musculocutaneous Injury: Comparing Double Fascicular Nerve Transfer With Conventional Nerve Grafting.
4. J Hand Surg Am. 2015 Oct;40(10):2003-6. doi: 10.1016/j.jhsa.2015.06.122. Epub 2015 Aug 14. PMID:26281978

5. Birch R, Misra P, Stewart MP, Eardley WG, Ramasamy A, Brown K, Shenoy R, Anand P, Clasper J, Dunn R, Etherington J.

6. Nerve injuries sustained during warfare: part II: Outcomes.

7. J Bone Joint Surg Br. 2012 Apr;94(4):529-35. doi: 10.1302/0301-620X.94B4.28488. PMID:22434471

8. Stoebner AA, Sachanandani NS, Borschel GH. Upper and lower extremity nerve injuries in 
pediatric missile wounds: a selective approach to management.

9. Pediatr Surg Int. 2011 Jun;27(6):635-41. doi: 10.1007/s00383-010-2734-y. Epub 2010 Sep 21.

PMID:20857295

10. Birch R. Causalgia: a restatement. Neurosurgery. 2009 Oct;65(4 Suppl):A222-8. doi: 10.1227/01.NEU.0000358956.2801 8.84. Review. PMID:19927072

11. Ecklund JM, Ling GS. From the battlefront: peripheral nerve surgery in modern day warfare.

12. Neurosurg Clin N Am. 2009 Jan;20(1):107-10, vii. doi: 10.1016/j.nec.2008.07.022.

Review.

PMID:19064183

13. Secer HI, Daneyemez M, Tehli O, Gonul E, Izci Y. The clinical, electrophysiologic, and surgical characteristics of peripheral nerve injuries caused by gunshot wounds in adults: a 40-year experience. Surg Neurol. 2008 Feb;69(2):143-52; discussion 152. Epub 2007 Oct 29.PMID:17967482

14. Roganović Z, Misović S, Kronja G, Savić M. Peripheral nerve lesions associated with missile-induced pseudoaneurysms. J Neurosurg. 2007 Oct;107(4):765-75.

PMID:17937221

15. Volgas DA, Stannard JP, Alonso JE. Current orthopaedic treatment of ballistic injuries.

Injury. 2005 Mar;36(3):380-6. Review. PMID: 15710154

16. Suneson A, Hansson HA, Seeman T. Central and peripheral nervous damage following high-energy missile wounds in the thigh. J Trauma. $1988 \quad$ Jan;28(1 Suppl):S197-203. No abstract available. PMID: 3339686 